УДК 330.88

\title{
СОВЕРШЕНСТВОВАНИЕ ИНСТИТУЦИОНАЛЬНОЙ МАТРИЦЫ БЕЛОРУССКОЙ ЭКОНОМИЧЕСКОЙ МОДЕЛИ
}

\author{
А.И. ЛУЧЕНОК \\ д-р экон. наук, профессор, заведующий отделом \\ макроэкономической и финансовой политики \\ ГНУ «Институт экономики НАН Беларуси», г. Минск
}

\begin{abstract}
Аннотация
Статья посвящена проблемам формирования и развития белорусской институичиональной матрицы, определяющей специфику социально-экономического развития Республики Беларусь. Показаны трудности импортирования институтов из другой институциональной матрицы, определены основные пути реформирования национальной экономики с учетом специфики институционального развития. Даны рекомендации по совершенствованию инструментов согласования интересов различных сочиальных макрогрупп и учету общеначиональных интересов, а также по неинфляционному стимулированию внутреннего спроса.

Ключевые слова: интересы. институцииональная матрица, институты, стимулирование.

\section{Abstract}

The article is devoted to the problems of formation and development of the institutional matrix that determines the specificity of the socio-economic development of Belarus. The constraints of importing institutions from other institutional matrix were revealed. The article defines the major ways of reforming of the national economy taking into account peculiarities of institutional development. Recommendations to improve the tools of coordination of interests of various social macrogroups given the priority national interests, as well as noninflationary stimulation of domestic demand have been developed.
\end{abstract}

Key words: interests, institutional matrix, institutions, stimulation.

\section{ВВЕДЕНИЕ}

Концепция институциональных матриц базируется на трудах Д. Норта, высказавшего точку зрения, что система общественных институтов образует институциональную матрицу, определяющую веер возможных траекторий дальнейшего развития [1, с. 147-148]. Один из наиболее активных русскоязычных разработчиков проблемы институциональных матриц - С.Г. Кирдина - включила в это понятие наряду с экономическими и политическими, также идеологические институты [2]. Ею также дано определение институциональной матрицы как устойчивой, исторически сложившейся системы базовых институтов, регулирующих взаимосвязанное функционирование основных общественных сфер экономической, политической и идеологической» [3, с. 425].

Вместе с тем, предложенные С.Г. Кирдиной критерии разделения институциональных матриц на $\mathrm{X}$ и $\mathrm{Y}$-подвиды вызывает определенные вопросы. Можно согласиться с ее общим подходом, что для X-матрицы в экономической сфере характерно перераспределение ресурсов через «центр», в политической - доминирование унитарного управления, в идеологической сфере - господство пропаганды приоритетов общества над индивидуальными потребностями, а базовые институты Y-матрицы в экономике построены на рыночных отношениях, в политике ориентируются на институ- 
тах федеративного устройства, а в идеологической сфере закреплено доминирующее значение индивидуальных ценностей.

\section{РЕЗУЛЬТАТЫ И ИХ ОБСУЖДЕНИЕ}

Вместе с тем, подходы С.Г. Кирдиной не всегда однозначно можно принять. В частности, вызывает сомнение ее тезис о том, что условием устойчивого развития $\mathrm{X}$-матрицы даже в слабоконкурентной среде является необходимость для экономических агентов снижать свои издержки. Более того, индексом эффективности $\mathrm{X}$-экономики ею рассматривается именно снижение издержек [4, с. 13,18$]$. В обоснование своей позиции С.Г. Кирдина ссылается на работы Х. Лейбенстайна. Однако указанный автор рассматривал проблемы эффективности на микроуровне и при этом часто жаловался на отсутствие обоснованной статистики, в результате чего ему приходилось обходиться «смутными впечатлениями» (“One cannot go beyond stating vague impressions since there is a lack of hard statistical evidence on this") [5, p. 397] и цитированием других авторов. Из его работы «Аллокативная эффективность в сравнении с $\mathrm{X}$-эффективностью» совершенно не следует, что автор рассматривал снижение издержек как специфику Х-матрицы. На самом же деле эту специфику он связывал с увеличением выпуска (output) и выделял три специфических элемента Х-эффективности: внутризаводскую мотивационную эффективность, внешнюю мотивационную эффективность и эффективность внерыночного воздействия (non market efficiency) [6, p. 407-408]. По нашему мнению, практика функционирования систем хозяйствования на основе централизованного регулирования показывает, что экономические модели, основанные на X-матрице, действительно ориентированы на увеличение объемов производства, и ее эффективность в существенной степени зависит от степени мотивированности работников в условиях административного доведения плановых заданий и частично централизованного распределения ресурсов. По сути дела, автор предлагает решать проблемы в X-матрице созданием мотивационного механизма и использованием нерыночных факторов регулирования.

Опыт Беларуси также свидетельствует, что в стране сформировалась институциональная X-матрица. Но для нашей страны не характерно стремление экономить на издержках, а приоритетом является достижение «прогнозных» показателей без должного учета возникающих при этом издержек. В частности, на уровне национальной экономики весьма велики трансакционные издержки от сверхнормативных запасов готовой продукции, а также от реализации ряда престижных, но не окупаемых проектов, чрезмерная поддержка отдельных предприятий в ущерб эффективности. При этом происходит активная «редистрибуция» (redistribution) ${ }^{*}$ финансовых ресурсов. По нашему мнению, в русскоязычной версии теории институциональных матриц вряд ли целесообразно использование этого англицизма. Вместо него более подходит русскоязычный термин «перераспределение».

Поэтому под Х-результативностью мы понимаем достижение экономического роста на основе применения преимущественно нерыночных инструментов стимулирования путем перераспределения ресурсов и экономического стимулирования работников за достигнутые результаты. Применительно к сложившейся белорусской институциональной системе это означает, что одним из слабо развитых в настоящее время направлений повышения эффективности отечественного экономического механизма является создание комплексной системы экономического стимулирования работников

\footnotetext{
* В частности, С.Г. Кирдина пишет: «В отличие от обмена, предполагающего две стороны, что выражается соответствующей ему парой категорий купля-продажа, редистрибуция предполагает пару хозяйствующих субъектов и опосредующего их взаимодействия центра, благодаря которому происходит согласование движения хозяйственных потоков в редистрибутивных Х-экономиках» [7].
} 
на всех уровнях производства и реализации товаров и услуг. Поэтому одной из первоочередных задач совершенствования экономических отношений в институциональной $\mathrm{X}$-матрице является как объективная оценка деятельности трудовых коллективов и отдельных работников, так и увязка результатов их работы с системой поощрения. При этом такая система должна распространяться в первую очередь на государственные и огосударствленные предприятия, в то время как внутри организаций частной формы собственности мотивационная система более развита и эффективна.

Следует учесть, что и в Х-матрице перераспределяются не все, а лишь часть ресурсов. Но аналогичная ситуация складывается и в социально ориентированных государствах на основе Ү-матриц. Для выхода из противоречия С.Г. Кирдина ввела понятие доминантных и комплементарных институтов. К первым относятся институты, преобладающие в основной матрице, а ко вторым - в подчиненной матрице. Как в генетике доминантный ген, «подавляя» рецессивный, задает проявляющиеся признаки живого организма, так и доминантные институты определяют характер складывающейся в обществе институциональной среды, задают рамки и ограничения для действия комплементарных вспомогательных институтов [3, с. 427]. Однако такое деление на практике только запутывает ситуацию. Например, торговля на Белорусской валютно-фондовой бирже под жестким контролем Национального банка вроде бы показывает, что налицо доминантный институт X-матрицы, ориентированный на внерыночные инструменты регулирования. Тем более, что волатильность спроса и предложения валюты обычно слабо влияет на курс белорусского рубля, и импортируемый из Yматрицы закон спроса и предложения как бы почти не работает и предстает явно комплементарным институтом. Но такая ситуация сохраняется лишь определенный период времени. Наступает момент, когда предложение иностранной валюты начинает сильно отрываться от спроса и происходит резкая девальвация. Вот тогда и выясняется, что глубинные процессы отражают именно закон спроса и предложения, а не внерыночное регулирование со стороны Национального банка. В экономике Беларуси несложно найти и другие сферы, где в среднесрочном и долгосрочном периодах тенденцию определяют рыночные отношения. Но можно ли считать, что белорусская институциональная модель соответствует Ү-матрице? Нет, потому что деление на типы матриц определяется по основному признаку: какие отношения преобладают- централизованное управление или преимущественное рыночное регулирование.

Тип институциональной матрицы во многом определяет специфику создаваемой в стране модели социально-экономического развития.

Несмотря на активную пропаганду в Беларуси моделей, базирующихся на экономических теориях, входящие в так называемый «mainstream», распространение соответствующих учебников и образовательных программ, неоклассические подходы не прижились в белорусской институциональной среде, вследствие чего началась разработка альтернативной национальной экономической модели. Как отметили А. Сидорович, Г. Бельская, В. Чувакина, В. Кульков, появление национальных моделей и типов экономических систем было следствием усложнения экономических отношений с увеличением числа направлений, школ и подходов к изучению экономики, необходимостью большего учета национального своеобразия стран [8]. Ю. Ольсевич показал, что методология «мейнстрима» отрабатывалась на исторических объектах США и стран Западной Европы и потому не содержит альтернатив экономического развития России и других постсоветских стран в переходных условиях [9].

К настоящему времени такая экономическая модель применительно к белорусским институциональным условиям в основном разработана и реализуется на практике. Она имеет следующую специфику.

Во-первых, основным элементом белорусской экономической модели является государство, ориентированное на использование административно-правовых методов 
регулирования с учетом соблюдения основных экономических законов (в том числе закона спроса и предложения, который в нашей стране никак нельзя считать комплементарным институтом). Создана государственная вертикаль власти, включающая в себя не только республиканские структуры и органы управления по отраслевому принципу, но региональные управленческие органы, обеспечивающие проведение государственной политики на местах. Принципиальная специфика методов управления в деятельности региональных структур отсутствует, что делает систему государственного управления страной единообразной. В результате методы регулирования хозяйственных процессов в Беларуси существенно отличаются от рекомендуемых классическими экономическими теориями для Ү-матриц, в которых роль государства в хозяйственной деятельности минимизирована, господствует конкуренция и цены устанавливаются исходя из спроса и предложения, а экономические агенты ведут свою хозяйственную деятельность исключительно исходя из их собственных интересов.

Во-вторых, в основу формирования белорусской системы управления были положены такие институты государственного регулирования, которые принуждают субъекты хозяйствования к действиям в первую очередь в соответствии с принимаемыми административными решениями. При этом применяемые государственные нормы и правила (институты) в большинстве случаев позволяют устранять наиболее серьезные аномалии в экономической деятельности.

В-третьих, созданная модель поддается реформированию на основе рыночных институтов в ограниченных рамках, так как базируется на Х-матрице. Именно поэтому попытки повысить эффективность хозяйствования обычно не затрагивают коренное преобразование отношений собственности. В самом деле, широкая реструктуризация отношений собственности и активная приватизация государственных предприятий существенно повлияли бы на властные полномочия государственных органов управления, а значит подставили бы под удар базисную черту экономической модели на основе X-матрицы. По этой причине появляются мнения, что реформы лучше отложить, поскольку в Беларуси преобразования должны осуществляться эволюционно, поэтапно, умеренно и осторожно, без ущемления роли государства в регулировании экономических процессов. При этом неизбежно вставал вопрос об институциональной специфике белорусского государства.

Один из основоположников неоинституциональной теории Д. Норт выделял два вида государства - контрактное и эксплуататорское [10]. Очевидно, что первый вид государства базируется на Y-матрице, а второй- на X-матрице. На самом деле видов или социально-экономических моделей может быть множество. Анализ показал, что для белорусских условий ни контрактная, ни эксплуататорская модели не подходит, поскольку экономическое развитие в Республике Беларусь происходит при доминирующем преобладании государственной собственности и осторожном проведении институциональных и структурных реформ. Важную роль в белорусской модели играет поддержание уровня благосостояния домашних хозяйств даже в ущерб эффективности. Поэтому, принимая во внимание разработки Ф. Перру о «доминирующей экономике» [11], мы считаем целесообразным использование для характеристики белорусской институциональной среды термина «доминирующее государство», а саму экономическую модель, в которой государственное управление преобладает над рыночным (косвенным) регулированием «доминантной моделью». Она ориентирована на максимальное развитие государственных институтов регулирования хозяйственной жизни с обеспечением административного контроля за хозяйственной деятельностью в первую очередь государственных предприятий, а также предприятий с долей государственной собственности (которые преобладают в белорусской экономике) с активным воздействием на их хозяйственную деятельность [12]. 
Как и всякая система, белорусская альтернативная экономическая модель обладает определенными достоинствами и недостатками. К ее достоинствам можно отнести следующие характеристики.

Во-первых, государственная власть направляет хозяйственную деятельность на достижение максимального эффекта в административном понимании этого термина. Однако при этом могут ущемляться интересы отдельных участников экономических отношений с ослаблением мотивационного механизма.

Во-вторых, белорусская практика показывает, что для усиления действенности централизованного государственного регулирования активно применяются рычаги ресурсного стимулирования, основанного на неравенстве доступа экономических агентов к ограниченным ресурсам. На современном этапе основным видом таких ресурсов являются кредиты, процентные ставки, по которым хозяйствующие субъекты льготируются из бюджетных средств. Основополагающая посылка о целесообразности концентрации основных ресурсов страны в руках государства на основе X-матрицы приводит к тому, что централизованное распределение ресурсов в экономическом, идеологическом и политическом плане априори предполагается отвечающим оптимуму по Парето, ибо в этом случае считается, что только государство знает кому и сколько необходимо предоставлять льготных ресурсов.

Государство, предоставляя субъектам хозяйствования финансовую помощь на льготных условиях, обычно дополняет их мерами административного характера. Например, предоставление долгосрочного льготного кредита под инвестиционный проект обычно связано с личной ответственностью руководителя предприятия за его своевременное освоение и достижение оговоренных в бизнес-плане техникоэкономических показателей. Такая политика связывания предоставления ресурсов с личной ответственностью позволяет повышать эффективность государственного управления «из центра», усиливая зависимость экономических агентов от управленческих структур.

В-третьих, в условиях высоких внешнеэкономических рисков, проблем с обеспечением сбалансированности внешнеторгового сальдо, вытекающего отсюда нестабильного курса белорусского рубля и достаточно высоких темпов инфляции государственная политика перераспределения финансовых ресурсов, предусматривающая субсидирование льготных процентных ставок, позволяет реализовывать программу модернизации национальной экономики. Это было бы невозможно при преимущественно рыночных отношениях в экономике, построенной на Ү-матрице.

B-четвертых, как сложная социально-экономическая система X-матрица заинтересована в своей сохранности с модификацией только внешних проявлений своих сущностных качеств (например, переименованием доводимых показателей с директивных на прогнозные или индикативные).

К недостаткам сложившейся в Республике Беларусь институциональной модели как формы проявления специфики Х-матриц можно отнести следующие моменты.

Во-первых, фактически административное перераспределение ресурсов в отрыве от их реальной цены (в том числе при предоставлении кредитных ресурсов ниже сложившейся рыночной процентной ставки) создает проблемы для эквивалентного обмена при рыночных отношениях. Но поскольку в белорусской экономической модели рыночные отношения с самого начала рассматривались как вспомогательный инструмент, то этот недостаток в административных структурах не считается существенным.

Во-вторых, в преимущественно административной институциональной модели возникают трудности импорта институтов, свойственных преимущественно рыночной системе. Именно поэтому в Беларуси не получили пока должного развития институты фондового рынка, купли-продажи земли, государственно-частного партнерства и т.д. Белорусская институциональная модель создала им несимметричные альтернативы. 
Например, вместо рыночной торговли облигациями реализуются обеспеченные финансовыми ресурсами государственные инвестиционные программы, формируются инвестиционные и инновационные фонды, которые ориентированы на перераспределение централизуемых государством средств. Можно дискутировать об эффективности такой замены, но система работает. Поэтому оказались ошибочными прогнозы западных консультантов, предсказывавших провал белорусской экономики на том основании, что либеральные подходы в белорусской экономике не приживаются и поэтому конечный крах экономики неизбежен.

В-третьих, в X-матрице сильнее проявляются негативные эффекты проблемы асимметричности (недостаточности и неточности) информации. Это обусловлено свойством административных систем приукрашивать свои результаты, что не может компенсироваться относительно слабо развитыми в таких системах рыночными отношениями. Кроме того, в Х-матрицах управленческие структуры стремятся занижать объем своих ресурсов, во-первых, для того, чтобы их не перераспределили «через центр» и, во-вторых, в целях создания резервов для выполнения заданий по принципу «исходя из достигнутого».

Наличие указанных недостатков приводит к возникновению институциональных ловушек, то есть тупиковых ситуаций, когда любое управленческое решение ведет лишь к ухудшению положения. Пример институциональной ловушки - предпринимаемые попытки внедрения индикативного планирования. На переходе к нему настаивают эксперты международных организаций и сторонники рыночных реформ. Но в белорусской институциональной матрице, относящейся к X-типу, не предполагается существенной децентрализации государственного управления, в том числе в сфере планирования. Поэтому принятые решения по переходу к индикативному планированию затруднят использование административно-директивных методов регулирования. В результате возникает институциональная ловушка в системе государственного планирования.

Другой пример институциональной ловушки - неудовлетворительное развитие в стране фондового рынка, который в экономиках рыночного типа служит инструментом эффективного перераспределения финансовых ресурсов. В белорусской экономике перераспределение указанных ресурсов осуществляется преимущественно через систему государственного управления (в том числе через ОАО «Банк развития Республики Беларусь»), поэтому фондовый рынок является вспомогательным рыночным инструментом и не получает должного развития. В 2014 г. внебиржевой объем сделок по фактической стоимости с акциями юридических лиц резидентов Республики Беларусь превышал биржевой оборот в 7,2 раза, а за 8 месяцев 2015 г. - в 332,2 раза.

Таким образом, импортирование институтов, не свойственных белорусской институциональной матрице, оказывается неэффективным, хотя в странах с преимущественно рыночной ориентацией свойственные Ү-матрице институты действенны и способствуют экономическому развитию.

С учетом достоинств и недостатков белорусской институциональной модели и для избегания институциональных ловушек органам государственного управления необходимо определиться с реализацией одного из двух сценариев дальнейшего реформирования национальной экономики.

По первому сценарию принимается решение о переходе от преимущественно централизованного управления к рыночной модели. В этом случае для избежания институциональных ловушек необходимо революционное реформирование сложившейся белорусской институциональной матрицы, в том числе демонтаж существующей системы государственного регулирования вместе с заменой сложившейся системы экономических отношений между органами власти различного уровня, а также их взаимоотношений с субъектами хозяйствования и населением. Такое реформирование бу- 
дет болезненным, приведет к переделу собственности и временному усугублению дисбалансов.

По второму сценарию в экономике Республики Беларусь сохраняется преимущественно централизованное управление, при котором:

- роль рыночных институтов признается вспомогательной, подчиненной требованиям обеспечения эффективности централизованного государственного регулирования;

- произойдет фактический отказ от индикативной системы планирования как противоречащей белорусской институциональной матрице;

- фондовый рынок будет использоваться как вспомогательный инструмент распределения капиталов в Беларуси, основные финансовые ресурсы по-прежнему распределяются через органы государственного управления и ОАО «Банк развития Республики Беларусь».

Важным элементом эффективного функционирования белорусской институциональной матрицы должен быть механизм преодоления возможных противоречий между интересами субъектов общественных отношений и достижение разумного компромисса в распределении благ. Он базируется на формировании соответствующих институтов, регулирующих в том числе права собственности, определяющих роль государственной и частной собственности в производстве материальных благ, распределение потребляемых и создаваемых ресурсов, развитие новых технологий, место страны в международном разделении труда.

Международный и белорусский опыт свидетельствуют о наличии на макроэкономическом уровне групп влияния, ориентированных на реализацию общих интересов членов группы. Эти группы непосредственно связаны с хозяйственной деятельностью, во многом формируют приоритеты в экономической политике и оказывают непосредственное воздействие на принимаемые государственные решения. Они обладают влиянием, которое позволяет им серьезно воздействовать на основные макроэкономические пропорции, определять специфику монетарной, фискальной и институциональной политики, существенно корректировать финансовые потоки в экономике. Такие укрупненные группы нами предложено назвать социальными макрогруппами (СМГ) с выделением следующих их функций: (а) учет интересов членов социальной макрогруппы и выработка на этой основе общегрупповых целей; (б) реализация интересов социальной макрогруппы через взаимодействие с органами государственного управления; (в) продвижение своих представителей в органы государственного управления для реализации своих групповых интересов; (г) пропаганда своих интересов в средствах массовой информации. Ведущими социальными макрогруппами в белорусской экономике являются: «Индустриально-промышленный комплекс»; «Аграрнопродовольственный комплекс»; «Строительный комплекс»; «Банковско-финансовая сфера»; «Домашние хозяйства» (население) [13].

Для обеспечения сбалансированного развития наряду с учетом приоритета государственных интересов необходимо нахождение компромисса на уровне социальных макрогрупп. При этом наряду с учетом интересов нефинансового (реального) сектора экономики необходимо уделять внимание реализации интересов социальной макрогруппы «Домашние хозяйства».

В условиях белорусской институциональной модели согласование интересов этих групп обычно происходит не за счет действия рыночных сил, а путем принятия решений органами государственной власти. При этом в систему институтов включаются механизмы принуждения [14]. Поэтому приоритетными задачами институциональной политики должно быть не только совершенствование формирования системы правовых институтов, регулирующих экономическую деятельность, но и повышение уровня разработки инструментов регулирования системы неформальных институтов, которые позволят более сбалансированно регулировать экономические интересы с целью полу- 
чения максимального эффекта от использования всех видов материальных, трудовых и финансовых ресурсов.

Следует также принять меры, чтобы ни одна из социальных макрогрупп не брала на себя функции единственного представителя общенациональных интересов, подчиняя под себя интересы других социальных макрогрупп. В частности, признавая роль Национального банка как выразителя общенациональных интересов по обеспечению монетарной сбалансированности, необходимо с осторожностью относиться к попыткам подчинения интересов реального сектора и домашних хозяйств политике сдерживания внутреннего спроса для недопущения инфляции. Такая политика ведет к долговременному экономическому спаду, кризису реального сектора экономики и снижению уровня жизни населения.

Для достижения баланса интересов внутренний спрос целесообразно расширять преимущественно неинфляционными инструментами регулирования национальной экономики.

Прежде всего, необходимо принципиально изменить механизмы государственной поддержки предприятий. Стимулировать нужно не производство товаров, которые в ряде случаев являются неходовыми по определению, а облегчать условиях реализации при наличии серьезных бюджетных ограничений как предприятий, так и населения.

В связи с этим неинфляционное стимулирование внутреннего спроса домашних хозяйств целесообразно осуществлять с помощью:

- предоставления рассрочек при покупке потребительских товаров;

- развития потребительского кредитования;

- снижения ставок по потребительским кредитам за счет средств, выделяемых на поддержку предприятий.

- Для увеличения внутреннего спроса целесообразно также выделение населению целевых денежных бонусов на покупку:

- сложнотехнических промышленных товаров;

- строительных материалов и мебели отечественного производства;

- дорогостоящих услуг, в том числе направленных на развитие качества человеческого капитала (частичная оплата образования, платных медицинских услуг, интернет-провайдеров и др.).

Для стимулирования внутреннего спроса целесообразно также активизировать кредитование субъектов хозяйствования с предоставлением льготных процентных ставок по ссудам на покупку отечественных товаров и услуг с соответствующим повышением процентных ставок по кредитам, предоставляемых на приобретение импортных товаров и услуг.

Для связывания денег населения целесообразно также развивать фондовый рынок с обеспечением условий для роста курса обращающихся на нем ценных бумаг. Для этого необходимо акционирование и вывод на фондовую биржу акций наиболее успешно функционирующих белорусских предприятий. При продаже акций следует отдавать приоритет миноритарным акционерам с ограничением покупки акций иностранными инвесторами. Зарубежных инвесторов целесообразно мотивировать к вложению в экономику Республики Беларусь прямых иностранных инвестиций в том числе для целей импортозамещения.

Для увеличения внутреннего потребительского спроса целесообразно увеличивать количество домохозяйств, для чего необходимо проведение активной демографической политики. Целесообразно также привлечение на постоянное место жительства высококвалифицированных мигрантов с тем, чтобы они на заработанные деньги не покупали валюту и не переводили ее за границу, а делали покупки товаров и услуг внутри Республики Беларусь. Кроме того, для повышения покупательной способности населения необходимо активизировать деятельность по переподготовке, реабилитации 
нетрудоспособного населения трудоспособного возраста, развитию бирж труда и системы социальных пособий.

С учетом необходимости проведения социально ориентированной экономической политики целесообразно проводить более активную политику по увеличению доходов населения путем:

- регулирования ставок минимальной оплаты труда;

- индексации выплат заработной платы работникам бюджетной сферы;

- обеспечение социальной защиты населения.

При этом для предотвращения роста темпов инфляции в обязательном порядке должно соблюдаться требование опережающего предложения потребительских товаров и услуг по сравнению с ростом доходов домашних хозяйств.

Необходимо также активнее вовлекать теневые доходы работников в систему социального страхования.

Следует также расширить сферу государственного заказа на отечественную продукцию и услуги, в том числе предоставления государственного заказа на научные исследовательские проекты.

\section{ВЫВОДЫ}

1. Одним из факторов недостаточной эффективности белорусской экономической модели является ее эклектичность в институциональном плане из-за попыток сведения воедино элементов различных институциональных систем, в том числе и чуждых белорусской институциональной матрице. Практика показала, что попытки импорта в белорусскую экономическую модель, базирующуюся на преимущественном использовании централизованного государственного регулирования и перераспределении дефицитных ресурсов, институтов преимущественно рыночной системы, приводит к возникновению институциональных ловушек, то есть тупиковых ситуаций при принятии управленческих решений.

2. Органам государственного управления необходимо определиться с реализацией одного из двух сценариев дальнейшего реформирования национальной экономики.

По первому сценарию принимается решение о переходе от преимущественно централизованного управления к рыночной модели. В этом случае для избегания институциональных ловушек необходимо революционное реформирование сложившейся белорусской институциональной матрицы, в том числе демонтаж существующей системы государственного регулирования и заменой сложившейся системы экономических отношений между органами власти различного уровня, а также их взаимоотношений с субъектами хозяйствования и населением. Такое реформирование будет болезненным, приведет к переделу собственности и временному усугублению дисбалансов.

По второму сценарию в экономике Республики Беларусь сохраняется преимущественно централизованное управление, при котором:

- роль рыночных институтов признается вспомогательной, подчиненной требованиям обеспечения эффективности централизованного государственного регулирования;

- произойдет фактический отказ от индикативной системы планирования как противоречащей белорусской институциональной матрице;

- фондовый рынок будет использоваться как вспомогательный инструмент распределения капиталов в Беларуси, основные финансовые ресурсы по-прежнему распределяются через органы государственного управления и ОАО «Банк развития Республики Беларусь».

3. В условиях белорусской институциональной модели согласование интересов различных социальных макрогрупп производится не за счет действия рыночных сил, а 
путем решений органов государственной власти. Поэтому приоритетными задачами институциональной политики должно быть не только совершенствование формирования системы правовых институтов, регулирующих экономическую деятельность, но и повышение уровня разработки инструментов регулирования системы неформальных институтов, которые позволят более сбалансированно регулировать экономические интересы с целью получения максимального эффекта от использования всех видов материальных, трудовых и финансовых ресурсов.

4. В белорусской институциональной модели необходимо определиться с приоритетами, относящимися к реализации общенациональных интересов. При этом следует принять меры, чтобы ни одна из социальных макрогрупп не брала на себя функции единственного представителя общенациональных интересов, подчиняя под себя интересы других социальных макрогрупп. В частности, признавая роль Национального банка как выразителя общенациональных интересов по обеспечению монетарной сбалансированности, следует с осторожностью относиться к попыткам подчинения интересов реального сектора и домашних хозяйств политике сдерживания внутреннего спроса. Такая политика ведет к долговременному экономическому спаду, кризису реального сектора экономики и снижению уровня жизни населения.

5.Для увеличения внутреннего спроса, который не противоречил бы интересам Национального банка как выразителя общенациональных интересов по обеспечению товарно-денежной сбалансированности, целесообразно провести следующие мероприятия не эмиссионного характера:

- принципиально изменить механизм государственной поддержки предприятий. Следует перейти от финансовой поддержки производства товаров к облегчению условий реализации с учетом ограниченных финансовых возможностей как предприятий, так и населения. Неинфляционное стимулирование внутреннего спроса домашних хозяйств целесообразно осуществлять с помощью предоставления рассрочек при покупке потребительских товаров; развития потребительского кредитования; снижения ставок по потребительским кредитам за счет средств, выделяемых на поддержку предприятий;

- предоставлять населению целевые денежные бонусы на покупку сложнотехнических промышленных товаров, строительных материалов и мебели отечественного производства, дорогостоящих услуг;

- активизировать кредитование субъектов хозяйствования с предоставлением льготных процентных ставок по ссудам на покупку отечественных товаров и услуг с соответствующим повышением процентных ставок по кредитам на приобретение импортных товаров и услуг;

- проводить более активную политику по увеличению доходов населения путем регулирования ставок минимальной оплаты труда; индексации выплат заработной платы работникам бюджетной сферы; обеспечение социальной защиты населения. Необходимо активное вовлечение теневых доходов работников в систему социального страхования;

- сократить подоходное налогообложение для низкооплачиваемых категорий населения;

- использовать фондовый рынок преимущественно как инструмент связывания свободных денег организаций и населения с обеспечением условий для роста курса обращающихся на нем ценных бумаг. Основные финансовые потоки в сложившейся институциональной системе по-прежнему будут проходить через органы государственного управления, исходящих из необходимости решения поставленных перед страной социально-экономических задач.

6. Одним из основных путей повышения эффективности экономического механизма в белорусской институциональной модели является создание комплексной системы экономического стимулирования работников на всех уровнях управления. По- 
этому одной из первоочередных задач совершенствования экономических отношений в институциональной Х-матрице является как объективная оценка деятельности трудовых коллективов и отдельных работников, так и увязка результатов их работы с системой поощрения.

\section{ЛИТЕРАТУРА}

1. Норт Д. Институты, институциональные изменения и функционирование экономи-ки. - М.: Фонд экономической книги "Начала", 1997 г.

2. Кирдина С. Г. Теория институциональных матриц (пример российского институционализма). [Электронный ресурс] - Режим доступа: http://www.kirdina.ru/doc/news /20feb06/2.pdf

3. Кирдина С.Г. Институциональные матрицы и развитие России: введение в X-Yтеорию. Издание 3-е, переработанное, и иллюстрированное. - СПб. : Нестор-История, 2014. -468 c.

4. Кирдина С. Г. Х-эффективность и Х-экономики: синтез теоретических подходов. - Экономический вестник Ростовского университета, 2007. Т. 5. № 2, с. 9-26.

5. Leibenstein H. Allocative Efficiency vs. "X-Efficiency". The American Economic Review, Volume 56, Issue 3 (Jun., 1966), p. 392-415.

6. «The main burden of these findings is that X-inefficiency exists, and that improvement in X-efficiency is a significant source of increased output. In general, we may specify three elements as significant in determining what we have called X-efficiency: (1) intra-plant motivational efficiency, (2) external motivational efficiency, and (3) nonmarket efficiency». Leibenstein H. Allocative Efficiency vs. "X-Efficiency". The American Economic Review, Volume 56, Issue 3 (Jun., 1966), p. 392-415.

7. Кирдина С.Г. Институциональные матрицы и развитие России: введение в X-Yтеорию. Издание 3-е, переработанное, и иллюстрированное. - СПб. : Нестор-История, 2014. - с. 376.

8. Сидорович А. О взаимосвязи экономической теории и стратегии государства // Экономист. 2008. № 11.; Г.С. Бельская, В.С. Чувакина Позволяет ли «мейнстрим» адекватно отражать российскую экономику. Вестник томского государственного университета. серия Экономика 2010, №1(9).

9. Кульков В. Национальное в экономической теории и в её вузовских курсах // Российский экономический журнал. 2004. № 4, с. 70.

10. Ольсевич Ю.Я. Современный кризис «мейнстрима» в оценках его представителей (предварительный анализ). - М.: Институт экономики РАН, 2013. - 46 с.

11. Норт, Д. Институциональные изменения: рамки анализа / Д. Норт // Вопросы экономики. - 1997. - № 3.

12. Ярцева, Н.В. Современные концепции экономической мысли / Н.В. Ярцева. Изд-во Алтайского госуниверситета [Электронный ресурс]. - 2003. - Режим доступа: http://irbis.asu.ru/mmc/econ/u_sovrcon/4.2.1.ru.shtml.

13. Лученок А.И. Использование неоинституциональных подходов в белорусской экономической модели. - Белорусский экономический журнал, 2005, № 2, с. 4-12.

14. Лученок А.И. Институциональные аспекты сбалансированного развития с учетом согласования экономических интересов.. - Макроэкономические аспекты обеспечения сбалансированности национальной экономики / А.И. Лученок [и др.]. - Минск : Беларускаянавука, 2015. С. 19-28.

15. Система экономических институтов Республики Беларусь / А.Е.Дайнеко [и др.]; под общ. ред. А.Е. Дайнеко ; Нац. акад. наук Беларуси, Ин-т экономики. Минск : Беларускаянавука, 2015, с.13.

Статья поступила в редакцию 19 ноября 2015 года. 